\title{
DO IDEAL AO REAL: AS CONSEQUÊNCIAS DAS MUDANÇAS CONCEITUAIS NA TEORIA DELIBERATIVA*
}

Claudia Feres Faria

O fato de uma teoria normativa parecer ultrapassada não pressupõe que ela esteja errada. Entretanto, quando a teoria passa a ser vista como ultrapassada precisamente porque ela não se enquadra à realidade empírica que ela alegadamente justifica, talvez alguma coisa mais profunda esteja faltando

(DryZek, 2000, p. 26).

A controvérsia entre fatos e normas é uma característica da teoria política moderna em geral e da teoria democrática em particular (Sartori, 1994; Habermas, 2006). Um exemplo emblemático dessa controvérsia pode ser encontrado no debate recente, dentro da teoria deliberativa, acerca do alcance do conceito de deliberação. Esse conceito é bastante contestado e hoje passa por modificações importantes (Faria, 2010) que, em parte, resultam de pesquisas empíricas (Rosenberg, 2007; Thompson, 2008; Bächtiger et al., 2009). Embora reconheçam que ela alcançou a "maturidade" (Bohman, 1998), tais pesquisas ensejam um rico debate em torno dos pressupostos "clássicos" da teoria deliberativa. Analisar parte dessas importantes mudanças analíticas, motivadas pela controvérsia entre fatos e normas (Thompson, 2008; Bächtiger et al., 2009), constitui objeto deste artigo.

* A primeira versão deste artigo foi apresentada no GT de Teoria Política da Associação Brasileira de Ciência Política (ABCP) de 2010. Sou grata ao coordenador desse GT, assim como ao parecerista anônimo desta revista pelas sugestões e críticas proferidas. Antecipo, entretanto, que os problemas remanescentes são de minha inteira responsabilidade. 
Ao debaterem as potencialidades e os limites de algumas versões da teoria deliberativa, notadamente a habermasiana ${ }^{1}$, parte dos deliberacionistas sugerem novos elementos que, embora criativos do ponto de vista metodológico - uma vez que nos oferecem novas ferramentas para dar conta da realidade que buscamos analisar -, não são neutros do ponto de vista analítico. Para examinar a questão proposta, este artigo descreverá uma dessas sugestões, qual seja, a ideia de um sistema integrado de deliberação ${ }^{2}$.

Além de apresentar uma visão mais geral do que consiste esse sistema (Mansbridge et al., 2012), analisaremos em detalhe três propostas específicas vinculadas às elaborações de Mansbridge (1999, 2007), Goodin (2008) e Hendriks (2006). $\mathrm{O}$ valor dessas propostas reside em tratarem a dinâmica deliberativa não mais como espaços unitários de deliberação, mas como uma "sequência integrada de momentos deliberativos". Nelas, a deliberação passa a se constituir como um entre os 64 diversos padrões de ação que conformam o processo político e cujas relações conformam esse sistema. Acreditamos que, se por um lado, essa modificação na dinâmica deliberativa gera ganhos metodológicos para a análise das instituições deliberativas, das relações e dos impactos destas nas políticas públicas; por outro, a forma como Mansbridge $(1999,2007)$ e Goodin (2008) a elaboram traz consequências analíticas importantes para essa teoria. Para operacionalizar tal estratégia metodológica, esses autores introduzem em seus modelos importantes noções, como as de autointeresse e de conflito. Esse movimento aproxima, a nosso ver, a abordagem deliberativa de antigas

\footnotetext{
${ }^{1}$ A ênfase no trabalho de Habermas decorre do intenso diálogo estabelecido entre ele e outros autores que buscam operacionalizar empiricamente os pressupostos da teoria moral tal qual apresentada na teoria da ação comunicativa (Habermas, 1984, 1987). Como exemplo importante desse diálogo, ver Bächtiger e Steiner (2005) e Bächtiger et al. (2009).

${ }^{2} \mathrm{O}$ uso da palavra sistema não pressupõe uma relação perfeita e previsível entre as partes. Segundo Mansbridge, ele pressupõe apenas uma inter-relação entre as partes onde mudanças em uma tendem a repercutir em outras (1999, p. 228).
} 
e conhecidas abordagens da teoria democrática, particularmente a pluralista e a neocorporativa.

Este artigo pretende analisar justamente as consequências dessas aproximações para o potencial crítico da teoria deliberativa. A pergunta que nos guia diz respeito aos impactos que a opção por uma versão supostamente mais realista de democracia deliberativa gera para este mesmo potencial crítico que, como se sabe, marcou o giro deliberativo da teoria democrática. Por fim, ofereceremos resposta a essas indagações.

\section{A teoria democrática deliberativa em questão: entre 0 ideal e o real}

Tornou-se rotineiro encontrarmos, após o giro deliberativo da teoria democrática, um conjunto de pesquisas e artigos que buscam precisar os elementos da deliberação à luz de evidências empíricas, dividindo-a em modelos de democracia deliberativa normativa e realista (Mansbridge, 2007; Mansbridge et al., 2009; Thompson, 2008; Bächtiger et al., 2009). Nesses trabalhos, a deliberação é analisada como um entre os diversos momentos do processo político e, assim, afere-se em que medida tais momentos são mais ou menos deliberativos. No lugar da noção abrangente de democracia deliberativa, passamos a ter a ideia de deliberação democrática (Mansbridge, 2007). Tal proposta carrega consigo não só mudanças na forma, mas também no conteúdo. Assim sendo, operam-se mudanças conceituais como aquelas referentes à definição de deliberação e seus componentes, bem como no que diz respeito a seus objetivos (a busca do bem comum ou do autointeresse) e os meios para alcançá-los (o consenso, o acordo ou a barganha).

No que diz respeito ao conceito, de Habermas (1997) a Bohman (1998), passando por Dryzek (2000) e Gutmann e Thompson (2004), é possível compreender tais mudanças 
como decorrência da necessidade de adequar o conceito "clássico" de deliberação às exigências empíricas. Daí as mudanças do discurso para o diálogo, do consenso para o acordo e deste para a demanda por justificação pública ${ }^{3}$.

Como veremos a seguir, Jane Mansbridge, Robert Goodin e Caroline Hendriks, ao localizarem a deliberação no interior de um processo democrático mais amplo, também reveem o conteúdo e os objetivos desta.

Jane Mansbridge nos oferece um conceito expandido de deliberação que inclui a fala cotidiana e a discussão informal (Mansbridge, 1999, 2007), a busca por autointeresse, a aceitação do conflito sobre interesses materiais e opiniões, bem como a legitimidade da agregação democrática (Mansbridge et al., 2009). Essas mudanças visam tornar o conceito mais "realista", mais próximo da "política como ela é", ao oferecer a seus pressupostos uma versão empiricamente factível. O sistema deliberativo é, então, composto por discursos for66 mais e também por falas informais e cotidianas entre atores comuns e políticos, tais como representados e representantes eleitos e não eleitos, ativistas e não ativistas e os profissionais da mídia. Através dele, os atores poderão compreender melhor o que querem e necessitam, tanto individual quanto coletivamente. O objetivo da deliberação passa a ser, portanto, esclarecer os termos do conflito, tentar conformá-lo e não mais a busca do consenso em torno do bem comum. Não obstante, embora o sistema precise ser julgado segundo padrões mais flexíveis para acomodar o caráter mais informal das partes no seu interior, ele não deve perder de vista alguns critérios importantes através dos quais se julga a boa deliberação. Critérios como publicidade, reciprocidade e controle se mantêm, assim como o conceito de razão pública, que, entretanto, deve ser reformulado de modo a envolver a emoção e a paixão (Mansbridge et al., 2009, p. 222).

\footnotetext{
${ }^{3}$ Para uma análise destas mudanças, ver Faria (2010).
} 
Goodin (2008) endossa igualmente a ideia de sistema ao propor um sistema sequenciado de momentos deliberativos que se contrapõe à versão padrão da democracia deliberativa que vê o agente deliberativo como único e que compartilha o mesmo objetivo entre todas as partes componentes deste mesmo sistema. Apoiando-se na mesma motivação de Mansbridge et al. (2009) - ou seja, buscar dar maior realismo à teoria deliberativa -, Goodin argumentará que, sendo a política composta de agentes plurais, com interesses conflitantes, que desempenham papéis diversificados em todo o processo político, o processo deliberativo deve ser visto igualmente de forma distribuída, com diferentes agentes que desempenham papéis deliberativos também diferentes. A justificativa para tal modelo repousa na crença, comum na teoria democrática, que, em grande escala, a deliberação interpessoal deve assumir formas delegadas, cujo exemplo paradigmático é o Legislativo. Neste, as deliberações são distribuídas entre comissões e plenário, cada um deles com regras próprias em decorrência tanto do tamanho quanto das funções diferentes que desempenham.

Ainda segundo Goodin, é possível pensar outros espaços onde as deliberações em subunidades servirão como inputs para a deliberação em grupos maiores, com novas responsabilidades deliberativas. Como entre as comissões e o plenário do Congresso, nesses outros espaços, as regras e a forma de conduzir a deliberação também não serão as mesmas. Goodin (2008) assegura que é possível esperar realisticamente (o grifo é dele) que virtudes deliberativas diferentes sejam encontradas em diferentes estágios do processo deliberativo, embora não mais como no modelo deliberativo ideal.

Do mesmo modo que Mansbridge (2007), Goodin também acredita que, apesar de a comunicação entre as partes não ser um jogo cooperativo, é possível a formação de um compromisso recíproco entre elas, mas nunca o consenso racionalmente motivado. As partes buscarão 
negociar e barganhar interesses e não somente trocar razões de maneira respeitosa. O contexto é, portanto, caracterizado pelo conflito, embora não só, pois poderão existir espaços para a concessão recíproca e para os argumentos razoáveis na construção de decisão vinculantes.

Hendriks (2006), por sua vez, também propõe uma terceira via para compatibilizar esferas múltiplas de deliberação através de um modelo integrado de deliberação. Ao partir de um conceito espacial desta, ela afirma que tal prática pode ocorrer em vários espaços públicos, incluindo parlamentos, partidos, fóruns e igrejas. Essa pluralidade de práticas conforma um sistema que envolve um conjunto de arenas através das quais tipos particulares de atividades ocorrem, tais como as práticas comunicativas que promovem a reflexão crítica e política. Assim, na perspectiva de Hendriks, o sistema se caracteriza por múltiplas esferas discursivas que podem ser formais, informais ou mistas, cujas formas de comunicação 68 também variam, indo desde o questionamento, a contestação, a negociação até ao consenso. Algumas são mais estruturadas que as outras; algumas são mais públicas e inclusivas; algumas são promovidas pelo estado ao passo que outras pelos atores da sociedade civil.

Uma vez que os atores possuem disposições variadas para deliberar nas diferentes esferas, é importante, adverte Hendriks, que o sistema como um todo promova a diversidade de espaços deliberativos. As esferas que combinam modos de deliberação formal e informal são importantes, pois, apesar das tensões, podem conectar mundos deliberativos diferentes - denominados macro e micro pela autora - povoados por atores diversos: ativistas, grupos de interesses, corporações, mídia, no macro, e parlamentares, consultores, acadêmicos, no micro. Tais espaços, ao entrarem em contato entre si e com cidadãos individuais, podem encorajar a troca de ideias entre atores com perspectivas diferentes, conectando o discurso público mais amplo com conversações e decisões das eli- 
tes políticas. Esse intercâmbio reflete uma constelação de discursos envoltos em um mesmo problema (Hendriks, 2006, p. 498). Ao conectar esferas que podem ser mais ou menos inclusivas ou mais ou menos populistas, essa autora também visa diferenciar seu modelo daquilo que ela denomina de "enclaves deliberativos".

As propostas analisadas neste artigo não exaurem, de forma alguma, as diversas tentativas existentes de compatibilizar esferas diferentes de deliberação. Exemplo pioneiro desse esforço pode ser encontrado no modelo "centro e periferia" de Habermas (1997) que busca combinar esferas públicas formais e informais no processo de aferição da vontade e da opinião política ${ }^{4}$. Não obstante, tais propostas - inseridas na segunda fase da teoria em tela, cuja preocupação reside na operacionalização dos princípios da teoria deliberativa - apresentam como ponto comum mudanças significativas tanto do ponto de vista analítico como do prático. Entre estas, podemos apontar a introdução de novos padrões discursivos tais como a fala informal e cotidiana e de diferentes padrões de comunicação que vão desde a emoção até a barganha. Tais mudanças impactam também os objetivos da deliberação que passam a visar não mais a busca do bem comum por meio do consenso racionalmente motivado, mas a construção de compromissos aceitáveis pelas partes. Busca-se, também aí, substituir a noção abrangente de democracia deliberativa por uma noção mais parcimoniosa de deliberação democrática, por meio da qual será possível aferir empiricamente em que medida espaços e instituições diferentes atuam de forma mais ou menos deliberativa, bem como quais relações entre eles serão necessárias para promover o sistema deliberativo como um todo ${ }^{5}$.

\footnotetext{
${ }^{4}$ A esse respeito, ver também Parkinson (2006) e Neblo (2005).

${ }^{5}$ Essas relações ainda não estão claras, sendo, portanto, objeto de pesquisa.
} 


\section{0 giro do giro: as consequências das mudanças conceituais na teoria deliberativa}

Como já mencionado na seção anterior, a definição habermasiana de deliberação, bem como os princípios que a guiam, dá suporte ao giro deliberativo ocorrido na teoria democrática (Dryzek, 2000) ${ }^{6}$. A partir daí emerge um profícuo diálogo entre os diferentes proponentes dessa teoria. Nesse sentido, vale a pena retomarmos tanto a definição oferecida por Habermas (1997), quanto os princípios que a balizam.

Segundo Habermas, a deliberação designa um "ato intersubjetivo de comunicação e argumentação cujo objetivo é alcançar um consenso sobre a solução para determinado problema social" (1997, p. 305). Para tanto, ela envolve: (a) argumentação: o intercâmbio regulado de informações e de razões entre partes que introduzem e examinam criticamente propostas; (b) publicidade e 70 inclusividade: todos aqueles que são possivelmente afetados pelas decisões devem ter chances iguais de tomarem parte de sua elaboração; (c) ausência de coerção externa: os participantes são soberanos à medida que só se encontram vinculados aos pressupostos da comunicação e às regras procedimentais de argumentação; (d) ausência de coerção interna: cada participante tem oportunidade igual de ser ouvido, de introduzir novos tópicos, fazer propostas e contribuições, assim como de criticar aquilo que foi proposto - tomada de posição sim/não é motivada somente pela força do melhor argumento; (e) acordos racionalmente motivados: estes podem ser, a princípio, desenvolvidos sem restrições ou retomados em

\footnotetext{
${ }^{6}$ Ao examinar as origens desse giro, Dryzek (2000) aponta duas fontes: o constitucionalismo liberal e a teoria crítica. Seguindo Chambers, justificamos a ausência de autores como Rawls (1999) neste artigo por considerar que ele, embora discuta alguns aspectos da democracia, não apresenta uma teoria democrática per se (Chambers, 2003, p. 308).
} 
qualquer momento, não obstante, as deliberações devem ser concluídas levando em conta a decisão da maioria devido ao seu nexo interno com a prática deliberativa, a regra da maioria justifica o pressuposto de que a opinião majoritária pode ser considerada uma base razoável para uma prática comum, até que a minoria convença a maioria do contrário; (f) regulação de todos os assuntos tendo em vista o interesse igual de todos: isso implica que certos temas e objetos, tradicionalmente considerados "privados", possam ser submetidos à discussão, em particular, aquelas questões que são publicamente relevantes, pois dizem respeito à distribuição desigual de recursos sobre os quais depende, de fato, o exercício dos direitos de comunicação e participação; (g) extensão das deliberações políticas à interpretação de necessidades e à transformação de preferências e enfoques pré-políticos: aqui, a força consensual dos argumentos não se apoia em um acordo sobre valores previamente desenvolvidos nas tradições e formas de vida comuns - esse "procedimento ideal de deliberação e de tomada de decisão" pressupõe uma associação que concorde em regular imparcialmente as condições de vida comum de seus cidadãos, pois aquilo que os agrupam é, em último termo, o laço linguístico que mantém a coesão de qualquer comunidade de comunicação (Habermas, 1997, pp. 305-6).

Os princípios retratados mostram que, nesse modelo considerado "clássico", o que se busca com a deliberação é uma solução comum para situações problemáticas, alcançada através de um consenso intersubjetivo. Ou seja, indivíduos, com interesses conflitantes sobre qual é a melhor solução para um determinado problema, deliberam entre si e convergem para a opção que acreditam ser a melhor para todos. Os diferentes interesses em jogo serão coordenados via discurso entre as partes no qual predomina a força do melhor argumento. Tal discurso baseia-se na lógica 
da ação comunicativa ${ }^{7}$ uma vez que os participantes adotam uma orientação voltada para o entendimento comum, agindo de forma sincera e verdadeira (Bächtiger et al., 2009). A legitimidade da solução alcançada deriva desse acordo comunicativamente alcançado. Nessa versão, tal qual afirmam Mansbridge et al. (2009), a deliberação é definida em oposição ao autointeresse, à barganha, à negociação, ao voto e ao uso do poder. Por essa razão, e em nome dos fatos sociais, ela deve ser reformulada ou "expandida".

Passa-se assim a propor (1) formas mais flexíveis de discursos, ao se enfatizar mais os resultados da deliberação do que o seu processo (Warren, 2007); (2) outras atividades que funcionem como influência comunicativa sob condição de conflito - a barganha, por exemplo (Mansbridge et al., 2009); (3) outras formas de comunicação além do discurso racional - a retórica, a narrativa etc. (Young, 2001); (4) uma concepção plural de bem comum e (5) a presença do conflito de 72 interesses e outros métodos não deliberativos de respondê-los (Mouffe, 2000; Connoly, 2005; Mansbridge et al., 2009). Nessa proposta expandida, o consenso deixa de se constituir em meta da deliberação e a política volta a ser concebida como a luta de interesses divergentes para realizá-los dado o "caráter erradicável do antagonismo promovido pelo pluralismo" (Bächtiger et al., 2009).

Esse giro do giro traz consequências? É possível de fato falar em "abandono dos ideais regulativos" da teoria deliberativa? (Thompson, 2008).

Antes de analisar tais consequências, é importante lembrar como o próprio Habermas (1997) retrabalha muitos dos

\footnotetext{
${ }^{7}$ Ação cujos participantes não se orientam primariamente ao próprio êxito, antes perseguem seus fins individuais sob a condição de que seus respectivos planos de ação possam se harmonizar entre si sobre a base de uma definição compartilhada da situação. Os planos de ação dos atores implicados nessa ação não se coordenam através de um cálculo egocêntrico dos resultados, mas mediante atos de entendimento (Habermas, 1984, p. 367).
} 
temas criticados ao formular seu modelo deliberativo de democracia. Embora os conceitos de esfera pública e de sociedade civil - este último como base social diferenciada da esfera pública - se mantenham como lócus de formação de uma vontade e de uma opinião pública através da ação comunicativa, o tipo de discurso passa a comportar questões não só de verdade e moralidade, mas também pragmáticas; questões sobre aquilo a ser feito para traduzir o consenso em decisões capazes de serem estabelecidas e negociadas quando os conflitos de valores e interesses tornam-se irredutíveis. Além do conteúdo do discurso, a argumentação racional aparece como uma entre outras formas de se resolver problemas de ação coletiva. Além desta, Habermas (2009) considera também a negociação e a barganha. Isso porque, segundo o autor, tais formas estão igualmente ligadas ao discurso uma vez que as pessoas em negociação têm de acordar sobre os termos da mesma ${ }^{8}$. No que diz respeito ao desfecho dessa interação, o consenso passa a ser uma das possibilidades, ao lado do compromisso legítimo e da cooperação (Habermas, 2009). Ademais, o autor passa a reconhecer uma pluralidade de públicos e atores que interagem entre si para formarem a opinião pública. Habermas passa a defender "uma comunicação sem sujeito, difusa" em contraste com a ideia de públicos formados somente pela interação face a face em pequenas comunidades (Dryzek, 2000, p. 25; Habermas, 1997, p. 360). Como consequência da complexidade social, "uma massa crescente de trocas

\footnotetext{
${ }^{8}$ Habermas, em seu diálogo com Elster, busca fundamentar esse argumento ao defender uma relação complementar entre normatividade e racionalidade (Habermas, 1997, pp. 338-9). Seguindo Repa, podemos afirmar que "[...] o paradigma proposto por Habermas, aquele que defende o entendimento recíproco entre sujeitos que falam e agem, não visa propor às ciências convencionais uma nova orientação teórica, mas uma nova orientação para a própria teoria crítica [...] que permita a convivência produtiva de diversos paradigmas teóricos, como o paradigma sistema e mundo da vida” (Repa, 2008, pp. 179-80). Entretanto, essa convivência é marcada pela crítica, ou seja, pela capacidade de criticar e colocar freios aos excessos da racionalidade instrumental (Nobre, 2004, p. 55).
} 
formais e informais, discussão, negociação, compromissos etc. [passam a ocorrer] em todos os estágios da política" (Habermas, 2009, p. 153).

Apesar das mudanças supracitadas, o debate entre as versões normativa e pretensamente realista de deliberação persiste e as consequências, a nosso ver, vinculam-se à aproximação das versões propostas daquilo que podemos chamar de pluralismo de segunda geração ${ }^{9}$ ou neocorporativismo (Mansbridge, 1995, 1999).

Em que pesem as diferenças de contexto no qual surgem, bem como dos propósitos que as envolvem, o ponto em comum dessas duas tradições reside na ênfase dada à dinâmica de grupos de interesses nas democracias liberais representativas. Enquanto a primeira defende uma multiplicidade de grupos econômicos e sociais que competem pela atenção do estado, a segunda postula mais especificamente a negociação entre capital e trabalho sob a égide do Estado (Held, 74 1994, pp. 194-5). Entretanto, em ambas, a legitimidade da ação do Estado é derivada da capacidade de intermediar e representar os interesses em jogo desses grupos.

Segundo Dahl (1989b), os procedimentos que regem essas relações estão inseridos em uma estrutura política que facilita a representação e a negociação desses interesses, bem como assegura que se coloquem em prática os resultados da competição estabelecida. A legitimidade do processo enseja a igualdade na representação, ou seja, ele só será legítimo se derivar de uma competição onde todos os interesses tiverem chances iguais de serem ouvidos e de influenciarem os resultados. Tal qual assegurado por Mansbridge (1999), a igualdade, nesse esquema, refere-se às oportunidades iguais para afetar os resultados.

Uma vez que a realidade social é marcada pela pluralidade de interesses e concepções de vida, a ideia de bem

\footnotetext{
${ }^{9}$ Embora não só, o principal proponente é Dahl (1989a, 1989b).
} 
comum deve ser descartada dado que, entre outras razões, a própria estrutura pluralista tende a reconciliar os interesses em competição por meio da distribuição e da atribuição de peso igual à representação dos interesses sociais.

Sanadas as distorções geradas pelas assimetrias de recursos materiais e simbólicos, a negociação e a barganha podem ocorrer livremente entre grupos cuja importância reside em sua capacidade de representar efetivamente os inúmeros interesses que se apresentam de forma desigual na sociedade. Os grupos podem aumentar essa capacidade de equalizá-los ${ }^{10}$. Para Mansbridge, tais grupos, ao adquirirem status e reconhecimento público, podem trazer para a negociação outros grupos, menos organizados, lançando luz às dificuldades de organizar interesses difusos e pouco representativos (1997, p. 137).

Se, por um lado, a ênfase nos grupos e nas condições em que são formados e atuam é importante para as democracias contemporâneas, podemos igualmente afirmar, seguindo Cohen e Rogers (1995), que a política não pode ser reduzida "ao bazar pluralista onde interesses e objetivos plurais competem entre si pela atenção do Estado", nem as representações sociais ao conflito capital e trabalho. Uma versão mais universalista da mesma deve ser requerida para dar conta de responder questões acerca da formação de sensibilidades públicas e as formas que tanto os cidadãos como o Estado podem promovê-las (Cohen e Rogers, 1995, p. 32). O ideal da barganha justa entre interesses de grupos, bem como os diferentes desenhos institucionais para operacionalizá-los, são preocupações importantes, mas limitadas para gerar julgamentos sobre quais temas serão relevantes, quais

\footnotetext{
${ }^{10}$ Os grupos podem fazer essa equalização de duas formas: 1) ao possibilitar meios para os indivíduos com menos recursos combinarem seus recursos com os de outros e emergirem como possibilidades reais de poder; (2) ao oferecerem representação para interesses que não são bem-organizados na política territorial (Cohen e Rogers, 1995, p. 34).
} 
grupos os representarão e quais as formas que melhor os representarão. Concentrar a discussão somente na justiça do sistema de representação e da agregação de interesses obscurece a importância da discussão sobre valores mais amplos, como aqueles relativos à formação de uma perspectiva cívica que, por sua vez, possibilitará a percepção da necessidade de formação e organização dos próprios grupos e de suas capacidades deliberativas. A ausência da ideia de uma esfera pública mais ampla - central na teoria deliberativa "clássica" - como lócus privilegiado de formação de uma opinião pública reflexiva que envolve mobilização, tematização e interpretações de diferentes temas, perspectivas e interesses, empobrece, a nosso ver, a proposta supostamente "realista" de deliberação democrática ${ }^{11}$. Tal esfera, vale lembrar, também faz parte de um sistema maior, caracterizado por diferentes níveis que comportam diferentes estilos de discurso e ação.

\section{$76 \quad$ Notas conclusivas: limites e potencialidades da ideia de sistema deliberativo}

A nosso ver, a principal potencialidade da ideia de sistema deliberativo é a de precisar as condições e os contextos através dos quais a deliberação poderá produzir uma opinião pública mais informada e decisões vinculantes mais legítimas, tanto do ponto de vista democrático quanto redistributivo. Nesse sentido, a diferenciação entre esferas formais e informais de deliberação, tal qual preconizada por Habermas $(1997,2009)$ ao propor seu modelo discursivo de democracia, ganha relevância quando torna o engajamento cívico e a deliberação uma relação de soma positiva. Na primeira, como defende o autor, ter-se-ia a possibilidade da formação de uma opinião pública informal que constitui a infraestrutura participativa das

\footnotetext{
${ }^{11}$ Esta ausência é mais sentida nos modelos de Goodin (2008) e Mansbridge (2007) do que de Hendriks (2006).
} 
democracias contemporâneas. Nesse caso, o padrão deliberativo se diferencia daquele operado na esfera pública formal, ou seja, no parlamento, nos tribunais e na administração. Tipos diferentes de padrões de ação e discurso habitam esses espaços, que são mais ou menos seletivos ao discurso racionalmente motivado.

Essa "diferenciação funcional de tipos de ação e da prática discursiva, que é dependente do lugar que a deliberação e a decisão ocupam no interior de um contexto mais amplo do sistema político como um todo”, possibilita, segundo o próprio Habermas (2005, p. 390), construir hipóteses mais específicas sobre a permeabilidade desses espaços aos diferentes tipos de deliberação e/ou negociações em função da diferença nos tipos de conflitos produzidos nesses espaços. Ou seja, o autor reconhece a diferenciação funcional nos tipos de ação e nas práticas discursivas como decorrência das diferenças de conflitos gerados em espaços diferentes.

Nesse esquema, a deliberação “do tipo clássico” poderá ser pensada como uma possibilidade em uma escala de tipos diferentes de ação e de prática discursiva. $\mathrm{O}$ momento através do qual se pesam razões entre sujeitos com o objetivo de tomar decisões públicas e legítimas poderá representar o ápice dessa escala, em que os cidadãos deparam com condições propícias e concordam em encontrar, mediante trocas de razões, soluções para os problemas comuns que os mobilizam. O caráter democrático desse momento derivará do tratamento igual àqueles que deliberam. Assim, para que a deliberação torne-se democrática, o processo terá de ser desenhado com o intuito de promover as habilidades deliberativas, respondendo, dessa maneira, às críticas derivadas da diferença nessas habilidades (Young, 2001; Phillips, 1995).

Resulta daí que, para alcançarem os procedimentos justos, os participantes devem se engajar na prática discursiva, avaliar o contexto e as circunstâncias nas quais ela pode ou não ocorrer. Como nos afirma Cohen (2007), se o 
contexto não for favorável, o problema não reside no ideal deliberativo, mas nas circunstâncias estabelecidas. Sendo assim, para melhorá-las, é necessário trabalhar em pelo menos duas frentes: na possibilidade de se criar, através do engajamento e da prática participativa, um julgamento público sobre as mesmas, assim como na possibilidade de transformar os resultados de tais práticas em regras e/ou procedimentos institucionais que ofereçam incentivos e protejam a deliberação.

Esse julgamento não precisa assumir somente a forma de razão, outras formas de comunicação poderão ser mobilizadas. Mas, como também nos lembra Cohen (2007), trocar razões não é a mesma coisa que a fala cotidiana defendida por Mansbridge et al. (2009). Essa fala não produz os resultados almejados à medida que o processo não enseja a reflexão requerida pela troca de razões. Isso não nos impede de pensar que o discurso informal possa servir como um treinamen78 to para a promoção das habilidades deliberativas (Hendriks, 2006). Entretanto, é preciso frisar, seguindo Warren, que a deliberação, como forma de comunicação, "é excepcional, constitui uma resposta às falhas das relações sociais, das instituições e sistemas e, por isto, ela é uma forma de comunicação exigente" (2007, p. 276).

Vale lembrar ainda que, na versão "clássica” da deliberação, a troca de argumentos bem como a demanda por justificação pública, mais do que as outras formas de comunicação, podem ensejar a revisão de posições, interesses e preferências, forjando uma perspectiva mais pública dos mesmos, sem, com isso, precisar descartar interesses e conflitos derivados de sua coordenação.

Não obstante, mesmo pensando em uma forma sistêmica, onde cada unidade funcionaria de maneira mais ou menos deliberativa, o grande desafio ainda é conectá-las com vistas a assumir uma forma mais integrada que gere impactos na vida dos cidadãos de uma comunidade. Em que pese tal 
dificuldade e a necessidade de resolvê-la, ao precisar os tipos corretos de controle e feedback entre eles, não é necessário, a nosso ver, abrir mão dos ganhos - mesmo que normativos oferecidos pela agenda dos deliberativos "clássicos".

\section{Cláudia Feres Faria}

é professora adjunta do departamento de ciência política da UFMG.

\section{Referências bibliográficas}

BÄCHTIGER, A.; STEINER, J. 2005. "Introduction". Acta Politica, v.40, n. 3, pp.153-168

et al. 2009. "Disentangling diversity in deliberative democracy: competing theories, their blind spots and complementarities". The Journal of Political Philosophy, v.18, n.1, pp.32-63.

BOHMAN, J. 1998. "Survey article: the coming age of deliberative democracy". The Journal of Political Philosophy, v.6, n.4, pp.400-25.

CHAMBERS, S. 2003. "Deliberative democratic theory". Annual Review of Politics Science, v.6, pp.307-26.

COHEN, J. 2007. "Deliberative democracy". In: ROSENBERG, S. (org.) Deliberation, participation and democracy: can the people govern? Basingstoke/ New York: Palgrave Macmillan, pp.219-36.

CONNOLLY, W. E. 2005. Pluralism. Durham, NC: Duke University Press.

COHEN, J.; ROGERS, J. (orgs.). 1995. Associations and democracy. London/ New York: Verso.

DAHL, R. 1989a. Um prefácio à teoria democrática. Rio de Janeiro: Jorge Zahar Editor.

1989b. Democracy and its critics. New Haven/London: YUP.

DRYZEK, J. S. 2000. Deliberative democracy and beyond: liberals, critics, contestations. New York: OUP.

FARIA, C. F. 2010. "O que há de radical na teoria democrática contemporânea: a análise do debate entre ativistas e deliberativos". Revista Brasileira de Ciências Sociais, v.25, n.73, pp.101-11.

GOODIN, R. E 2008. "Sequencing deliberative moments". In: Innovating democracy. New York: OUP, pp.186-203.

GUTMANN, A.; THOMPSON, D. 2004. Why deliberative democracy? Princeton: PUP.

HABERMAS, J. 1984. The theory of communicative action: reason and rationalization of society. Boston: Beacon Press, v.1. 
1987. The theory of communicative action: lifeworld and system - a critique of functionalist reason. Boston: Beacon Press, v.2.

1997. Between facts and norms: contributions to a discourse theory of law and democracy. Cambridge, UK: Polity.

2005. "Concluding comments on empirical approaches to deliberative politics". Acta Politica, v.40, n.3, pp.269-83.

2006. "Political communication in media society: does democracy still enjoy an epistemic dimension? The impact of normative theory on empirical research". Communication Theory, v.16, n.4, pp.411-26.

2009. Europe: the faltering project. Cambridge/ Malden, MA: Polity.

HELD, D. 1994. Modelos de democracia. Belo Horizonte: Paideia.

HENDRIKS, C. M. 2006. "Integrated deliberation: reconciling civil society's dual role in deliberative democracy". Political Studies, v.54, n.3, pp.486-508.

MANSBRIDGE, J. J. 1995. “A deliberative perspective on neo-corporatism”. In: COHEN, J.; ROGERS, J. (orgs.). 1995. Associations and democracy. London/New York: Verso, pp.133-47. 1999. "Everyday talk in the deliberative system". In: MACEDO, S. (org.) Deliberative politics: essays on democracy and disagreement. Oxford/ New York: OUP, pp.211-39. 2007. "Deliberative democracy or democratic deliberation?" In: ROSENBERG, S. (org.) Deliberation, participation and democracy: can the people govern? Basingstoke/ New York: Palgrave Macmillan, pp.251-72. et al. 2009. "The place of self-interest and the role of power in the deliberative democracy". Journal of Political Philosophy, v.18, n.1, pp.64-100. et al. 2012. "A systemic approach to deliberative democracy". In: PARKINSON, J.; MANSBRIDGE, J. J. Deliberative systems: deliberative democracy at the large scale. Cambridge: CUP, pp.1-26.

MOUFFE, C. 2000. "Deliberative Democracy or Agonistic Pluralism". Political Science Series, v.72, pp.1-17.

NEBLO, M. 2005. "Thinking through democracy: between the theory and practice of deliberative politics". Acta Politics, v.40, n.2, pp.169-81

NOBRE, M. 2004. A teoria crítica. Rio de Janeiro: Jorge Zahar.

PARKINSON, J. 2006. Deliberating in the real world: problems of legitimacy in deliberative democracy. Oxford/ New York: OUP.

PHILLIPS, A. 1995. The politics of presence. Oxford: Clarendon Press.

RAWLS, J. 1999. A theory of justice. Harvard: HUP.

REPA, L. 2008. "Jürgen Habermas e o modelo reconstrutivo de teoria crítica”. In: NOBRE, M. (org.) Curso livre de teoria crítica. Campinas: Papirus, pp.161-82. 
ROSENBERG, S. W. 2007. "An introduction: theoretical perspectives and empirical research on deliberative democracy". In: ROSENBERG, S. W. (Ed.) Deliberation, Participation and Democracy: can the people govern? Basingstoke/ New York: Palgrave Macmillan, pp.1-21.

SARTORI, G. 1994. A teoria da democracia revisitada. São Paulo: Ática. 2v.

THOMPSON, D. F. 2008. "Deliberative democratic theory and empirical political science". Annual Review Political Science, v.11, pp.497-520.

WARREN, M. E. 2007. "Institutionalizing deliberative democracy". In: ROSENBERG, S. W. (Ed.) Deliberation, Participation and Democracy: can the people govern? Basingstoke/ New York: Palgrave Macmillan, pp.272-88.

YOUNG, I. M. 2001. "Activists challenge deliberative democracy". Political Theory, v.29, n.5, pp.670-90. 


\section{(1) )}

\section{DO IDEAL AO REAL: AS CONSEQUÊNCIAS DAS MUDANÇAS CONCEITUAIS NA TEORIA DELIBERATIVA}

\section{CLÁUDIA FERES FARIA}

Resumo: A teoria deliberativa passa por mudanças significativas em seus pressupostos fundamentais. Para acomodar conceitos como autointeresse, poder e conflito e outras formas de comunicação, tais como barganha, essa teoria revisa atualmente os pressupostos que a orientava. Nesse movimento, ela se aproxima de outras abordagens clássicas da teoria democrática, como o pluralismo e o neocorporativismo. Este artigo tem um duplo objetivo: (1) analisar tais mudanças e (2) aferir as potencialidades e os limites das mesmas para a teoria em tela.

Palavras-chave: Teoria Deliberativa, Pluralismo, Neocorporativismo, Participação.

\section{FROM IDEAL TO REAL: THE CONSEQUENCES OF CONCEPTUAL CHANGES IN DELIBERATIVE THEORY}

Abstract: A deliberative theory has undergone significant changes in their fundamental assumptions. To accommodate concepts such as selfinterest, conflict and power and other forms of communication as a bargain, this theory has revised the initial assumptions that oriented it. In this move, it becomes more similar to other traditional approaches to democratic theory, such as pluralism and neo-corporatism. This article has two aims: (1) to analyze such changes; and (2) to evaluate the potential and limits of such changes to deliberative theory.

Keywords: Deliberative Theory, Pluralism, Neo-Corporatism and Participation.

Recebido: 07/08/2011 Aprovado: 15/03/2012 